\title{
Nonlinear Modeling and Analysis of Pressure Wave inside CEUP Fuel Pipeline
}

\author{
Qaisar Hayat, ${ }^{1}$ Liyun Fan, ${ }^{1}$ Enzhe Song, ${ }^{1}$ Xiuzhen Ma, ${ }^{1}$ Bingqi Tian, ${ }^{1}$ and Naeim Farouk ${ }^{1,2}$ \\ ${ }^{1}$ College of Power and Energy Engineering, Harbin Engineering University, Harbin 150001, China \\ ${ }^{2}$ Department of Mechanical Engineering, Red Sea University, 33311 Port Sudan, Sudan \\ Correspondence should be addressed to Liyun Fan; fanly_01@163.com
}

Received 10 January 2014; Accepted 21 March 2014; Published 23 April 2014

Academic Editor: Xi-Ming Sun

Copyright (c) 2014 Qaisar Hayat et al. This is an open access article distributed under the Creative Commons Attribution License, which permits unrestricted use, distribution, and reproduction in any medium, provided the original work is properly cited.

\begin{abstract}
Operating conditions dependent large pressure variations are one of the working characteristics of combination electronic unit pump (CEUP) fuel injection system for diesel engines. We propose a precise and accurate nonlinear numerical model of pressure inside HP fuel pipeline of CEUP using wave equation (WE) including both viscous and frequency dependent frictions. We have proved that developed hyperbolic approximation gives more realistic description of pressure wave as compared to classical viscous damped wave equation. Frictional effects of various frequencies on pressure wave have been averaged out across valid frequencies to represent the combined effect of all frequencies on pressure wave. Dynamic variations of key fuel properties including density, acoustic wave speed, and bulk modulus with varying pressures have also been incorporated. Based on developed model we present analysis on effect of fuel pipeline length on pressure wave propagation and variation of key fuel properties with both conventional diesel and alternate fuel rapeseed methyl ester (RME) for CEUP pipeline.
\end{abstract}

\section{Introduction}

Pressure inside CEUP fuel injection system can increase up to 1500 bars [1-3] depending upon the operating conditions of diesel engine. CEUP is an efficient high pressure fuel injection system for heavy and marine diesel engines that satisfies the Chinese emission regulations [2]. It consists of combination of high pressure pumps, solenoid control units, fuel pipe lines, and mechanical injectors. Change in CEUP fuel pipeline length affects the fuel injection characteristics due to superposition of pressure wave [3].

Advancements in diesel fuel injection system have also been accompanied by research on alternate fuel as replacement for conventional diesel fuel in diesel engines [4-10]. Characteristics of fuel injection depend not only on type of injection system but also on type of fuel [4-6]. Moreover the physical properties of fuel including density, acoustic wave speed, and bulk modulus also impact the injection characteristics $[4,6,7]$ of diesel engine. Empirical formulas for these physical properties have also been proposed $[9,10]$.

Pressure inside diesel fuel injection system pipeline has previously been modeled using principles of mass continuity and momentum conservation [11-14]. Classical viscous damped WE has also been utilized [15] to simulate pressure fluctuations in common rail (CR) fuel injection system. But these models [11-15] lack in considering the effects of frequencies on wave attenuation. It has been reported [1618] while working with ultrasonic impulse moving through viscous fluids in complex frequency domain that attenuation in viscous fluids increases with the increase of frequency. Relation of wave number, frequency, and damping parameter in WE can be found by assuming a sinusoidal solution in separable form of multiple frequencies $[18,19]$. As pressure in CEUP fuel pipeline fluctuates from low ( $\sim 50$ bars) to very high ( 1500 bars) in couple of ms depending on the operating conditions, it can be efficiently approximated as a pressure impulse flowing in viscous fluid. This approach of pressure modeling has not been reported for CEUP system other than our previously developed viscous damped models [20, 21].

In this paper a precise and accurate nonlinear numerical model of pressure wave including both viscous and frequency dependent damping has been developed in MATLAB for CEUP pipeline which accurately predicts the behavior of pressure wave and fuel properties with varying lengths of 


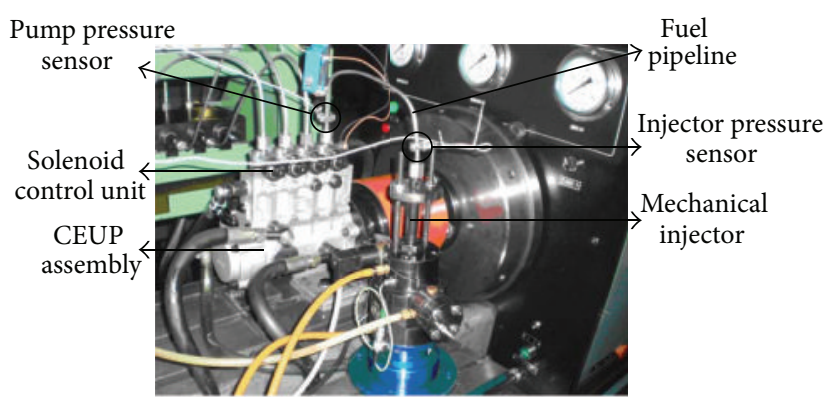

FIGURE 1: Experimental setup of CEUP fuel injection system.

pipeline. This model includes not only viscous damping due to axial viscous shear [15-19] but also frequency dependent friction along the pipeline wall $[18,19]$. The simulated results have been verified and evaluated by comparing them with our previously developed AMESim numerical model of CEUP $[20,21]$ and viscous damped mathematical model of pressure wave $[20,21]$, respectively. The study on the same model has been extended to simulate the effect of change in fuel pipeline length and behavior of key fuel properties for both conventional diesel and RME.

\section{Material and Methods}

2.1. Experimental Setup. Pump side and injector side pressures taken as Dirichlet boundary conditions for our mathematical model are recorded during lab experiments of CEUP fuel injection system as shown in Figure 1. Experiments have been carried out at combination of operating conditions mentioned in Table 1.

2.2. Nonlinear Numerical Modeling. Flow of fuel has been considered laminar and unidirectional, that is, from pipe side to injector side. Fuel is Newtonian, homogeneous, and without any bubbles; that is, cavitation has been neglected. Moreover, fuel pressure is considered constant across the cross section of rigid fuel pipeline.

Pressure wave inside pipe can be described by the following wave equation [15-21]:

$$
\nabla^{2} p-\frac{1}{c^{2}} \frac{\partial^{2} p}{\partial t^{2}}+\alpha \frac{\partial}{\partial t} \nabla^{2} p=0
$$

where $p, c, t$, and $\alpha$ are pressure, acoustic wave speed, time, and frequency independent constant parameter, respectively. $\alpha$ is given by

$$
\alpha=\frac{4 \eta}{3 \rho c^{2}}
$$

where $\eta$ and $\rho$ are absolute or dynamic viscosity and density, respectively. Initial and Dirichlet boundary conditions are

$$
\left.\begin{array}{lc}
p(x, 0)=P_{\text {initial }} & \frac{\partial p}{\partial t}(x, 0)=0 \\
p(0, t)=P_{\text {pump }} & p(L, t)=P_{\text {injector }}
\end{array}\right\} x \in(0, L), t \in(0, T),
$$

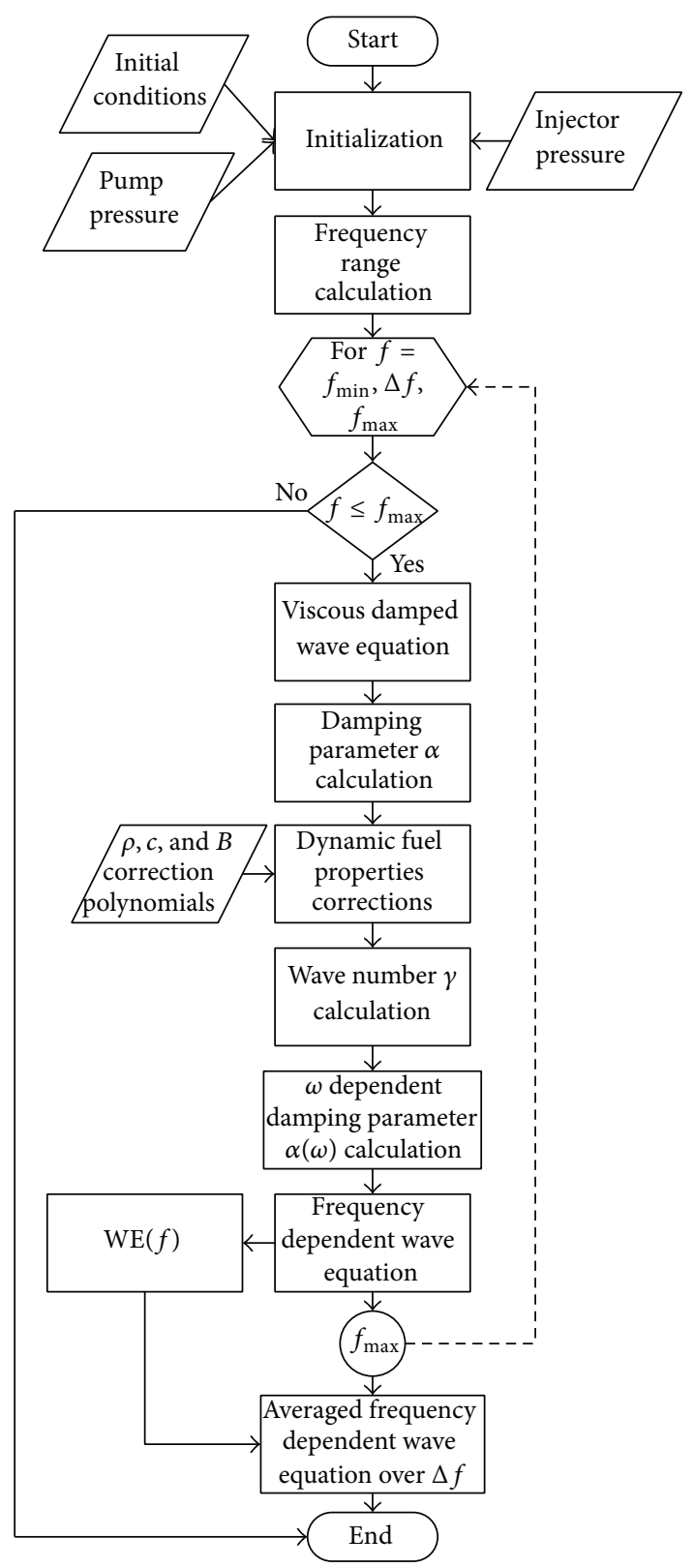

FIGURE 2: Flowchart of nonlinear model simulation.

where $P_{\text {initial }}, P_{\text {pump }}$, and $P_{\text {injector }}$ are initial pressure and experimentally measured pump side and injector side pressures, respectively. $L$ and $T$ are total length of fuel pipeline and total time of measured and simulated results, respectively.

The following function represents solution of (1) [19]:

$$
p(x, t)=\beta e^{i(\omega t+\gamma x)},
$$

where $\beta, \omega$, and $\gamma$ are amplitude, angular frequency, and complex circular wave number, respectively. Wave number can be obtained by using (1) and (4):

$$
\gamma_{1,2}= \pm \frac{\omega}{c} \sqrt{\frac{1}{1+\iota \omega \alpha}}
$$




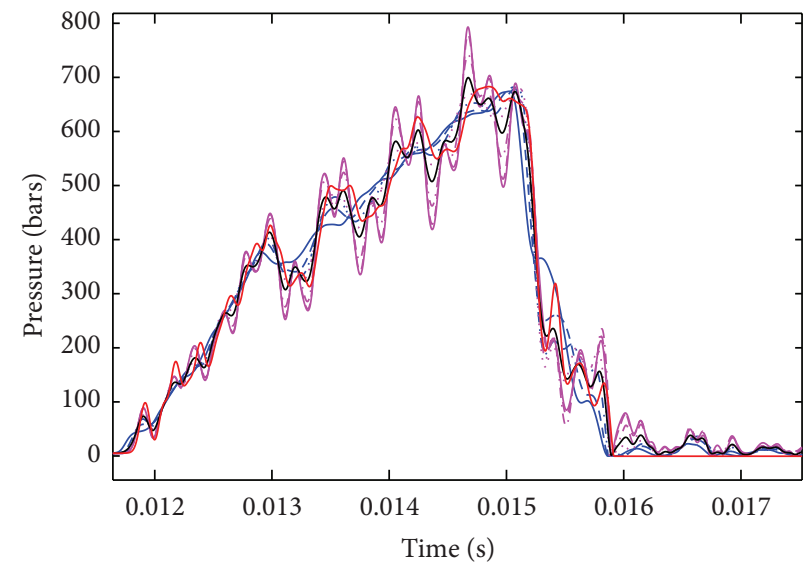

(a)

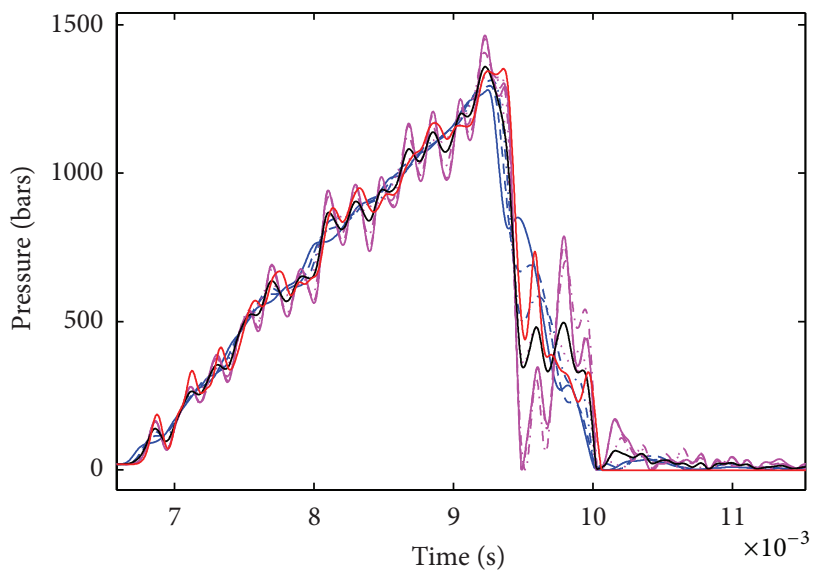

(c)

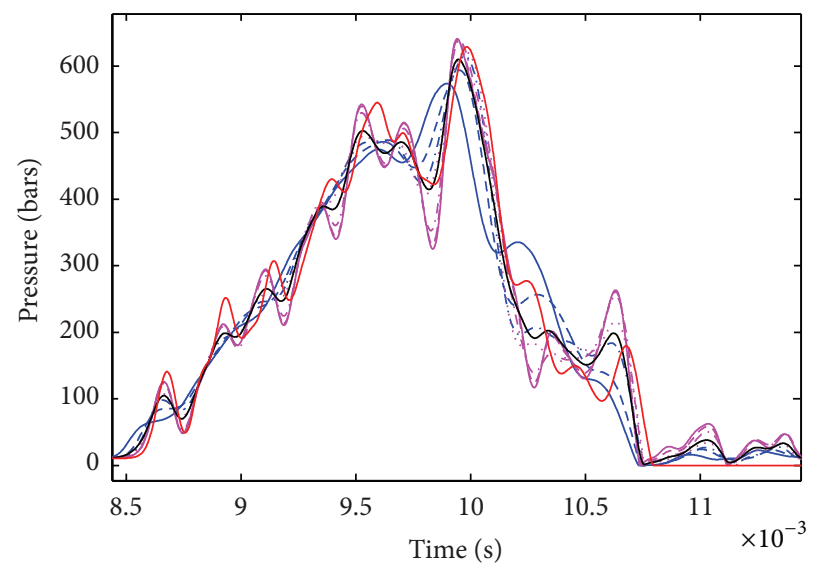

(b)

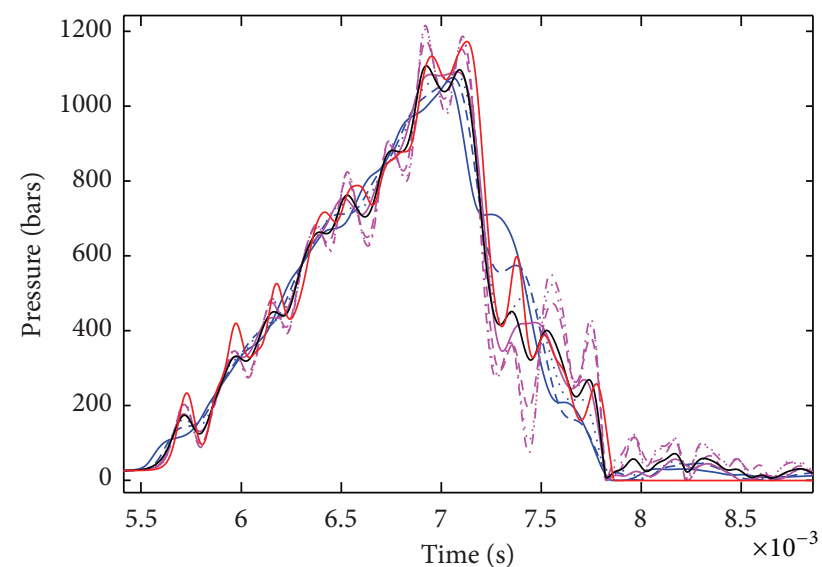

(d)

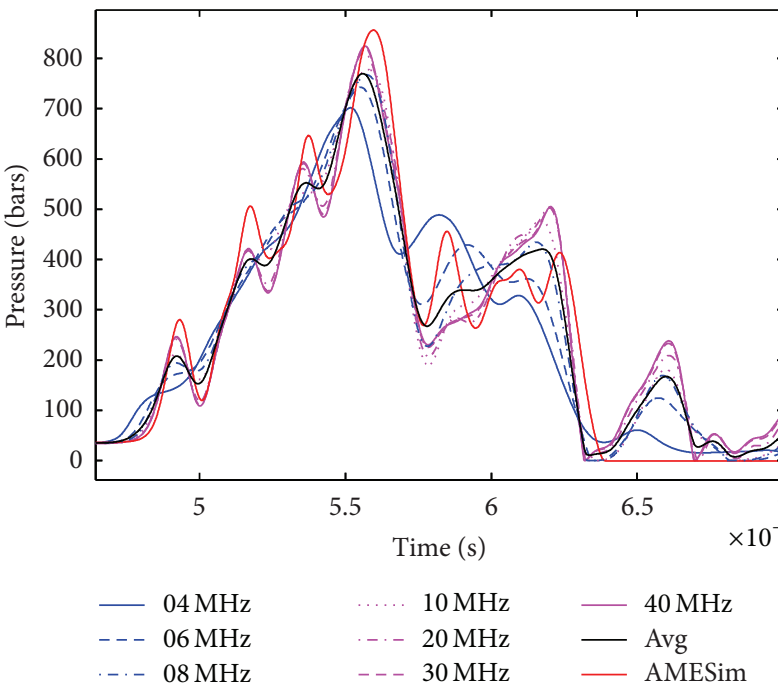

(e)

Figure 3: Effect of frequencies on mid pipeline pressures at (a) $500 \mathrm{rpm}, 10^{\circ} \mathrm{CA}$; (b) $700 \mathrm{rpm}, 6^{\circ} \mathrm{CA}$; (c) $900 \mathrm{rpm}, 14^{\circ} \mathrm{CA}$; (d) $1100 \mathrm{rpm}, 10^{\circ} \mathrm{CA}$; and (e) $1300 \mathrm{rpm}, 6^{\circ} \mathrm{CA}$. 


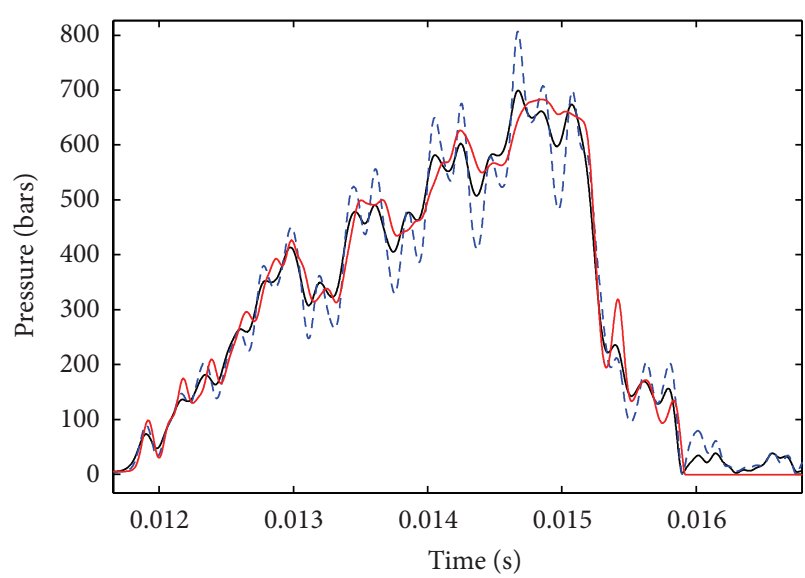

(a)

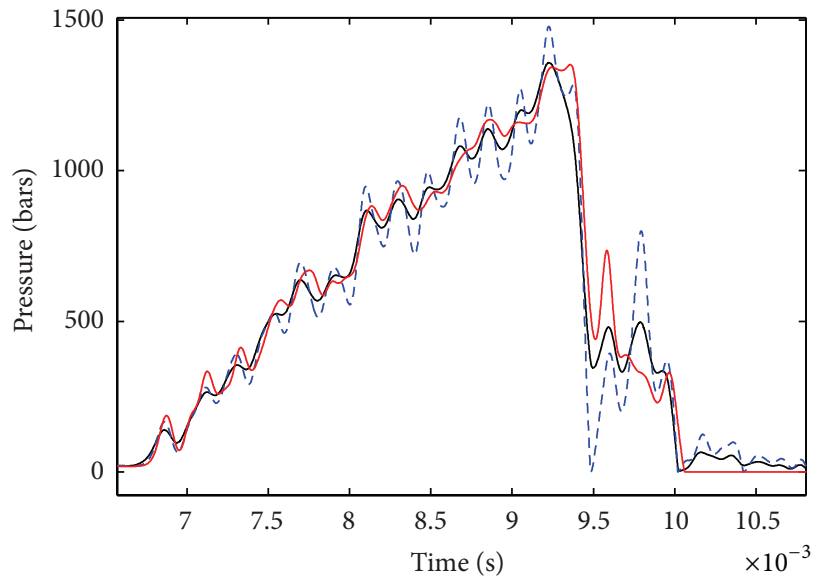

(c)

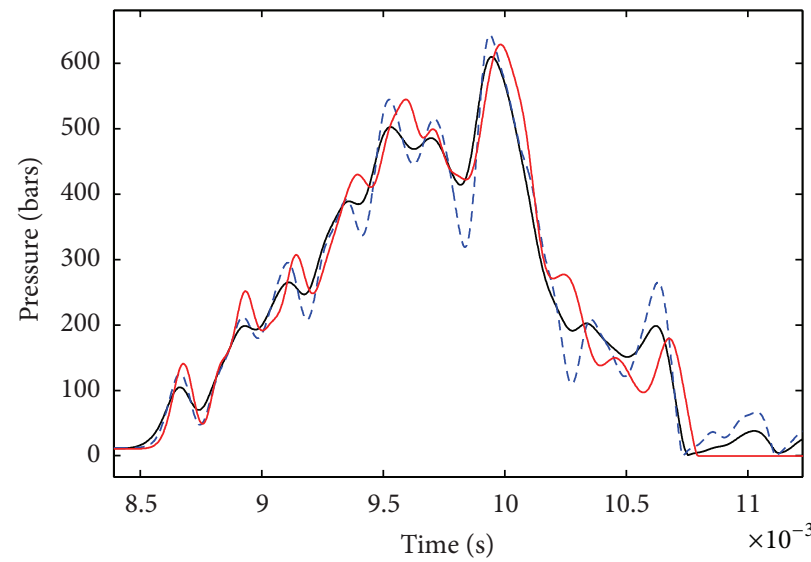

(b)

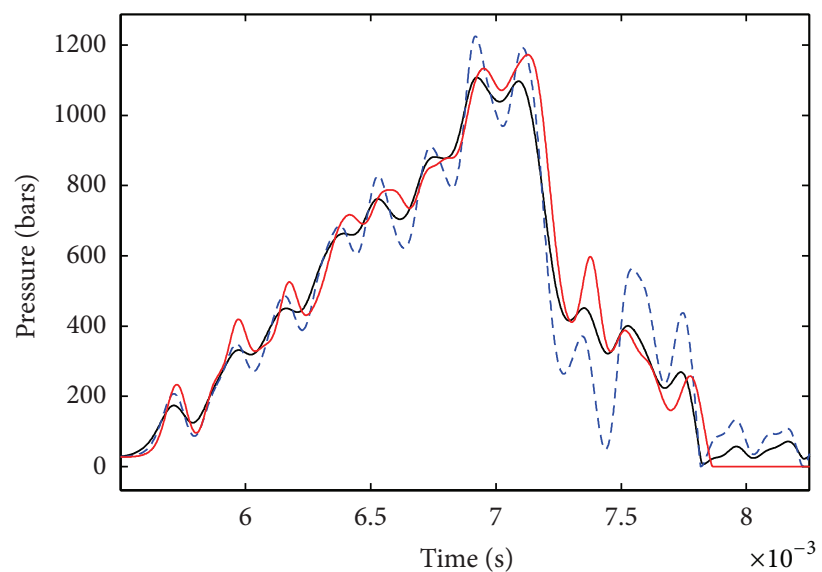

(d)

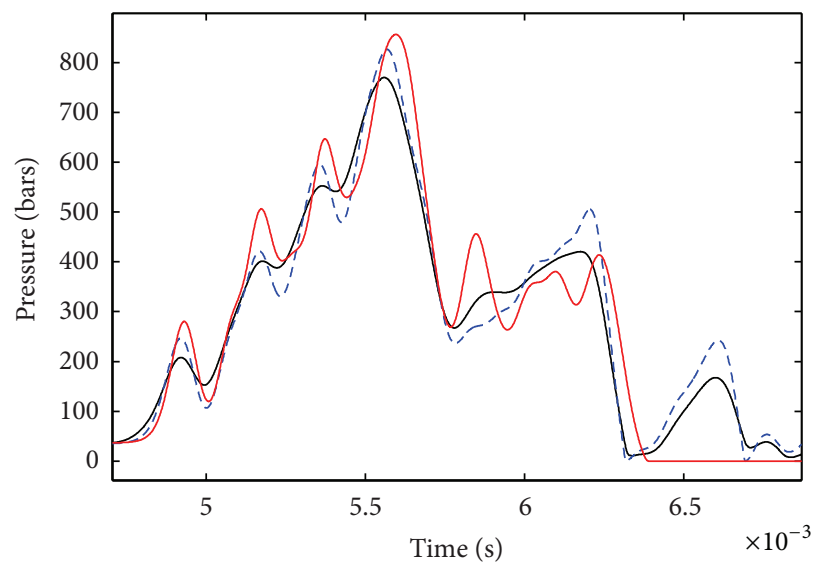

$\begin{array}{ll}\text { - } & \text { Nonlinear } \\ --- & \text { Viscous } \\ \text { _ } & \text { AMESim }\end{array}$

(e)

FIGURE 4: Comparison of mid pipeline pressures between nonlinear, viscous damped, and AMESim numerical models at (a) $500 \mathrm{rpm}, 10^{\circ} \mathrm{CA}$; (b) $700 \mathrm{rpm}, 6^{\circ} \mathrm{CA}$; (c) $900 \mathrm{rpm}, 14^{\circ} \mathrm{CA}$; (d) $1100 \mathrm{rpm}, 10^{\circ} \mathrm{CA}$; and (e) $1300 \mathrm{rpm}, 6^{\circ} \mathrm{CA}$. 
TABLE 1: Operating conditions for experiments.

\begin{tabular}{lcc}
\hline $\begin{array}{c}\text { Cam rotational speed } \\
(\mathrm{rpm})\end{array}$ & $\begin{array}{c}\text { Cam angle } \\
\left({ }^{\circ} \mathrm{CA}\right)\end{array}$ & $\begin{array}{c}\text { Pipe length } \\
(\mathrm{m})\end{array}$ \\
\hline $\begin{array}{l}500,700,900,1100 \text {, and } \\
1300\end{array}$ & $2,6,10$, and 14 & $\begin{array}{c}0.27,0.47 \text {, and } \\
0.67\end{array}$ \\
\hline
\end{tabular}

Equation (5) can be represented in its imaginary and real parts corresponding to decaying and oscillation of wave propagation, respectively. Positive imaginary part represents the frequency dependent damping near pipe wall [19]. Consider

$$
\gamma_{1,2}= \pm \frac{\omega}{c}\left(\sqrt{\frac{\sqrt{1+(\omega \alpha)^{2}}+1}{2\left\{1+(\omega \alpha)^{2}\right\}}}-\iota \sqrt{\frac{\sqrt{1+(\omega \alpha)^{2}}-1}{2\left\{1+(\omega \alpha)^{2}\right\}}}\right) .
$$

Circular wave number $\gamma$ is matched with damping $\alpha$ by the following relation [19]:

$$
\alpha(\omega)=\frac{\omega}{\iota c^{2} \gamma^{2}}-\frac{1}{\iota \omega} .
$$

Dynamic variations of keys fuel properties including density, acoustic wave speed, and bulk modulus during fuel injection process and varying pressures have been included using the following empirical formulas [9]:

$$
\begin{aligned}
\rho(x, t) & =D_{0}+D_{1} p(x, t)+D_{2} p^{2}(x, t), c(x, t) \\
& =C_{0}+C_{1} p(x, t)+C_{2} p^{2}(x, t), M(x, t) \\
& =M_{0}+M_{1} p(x, t)+M_{2} p^{2}(x, t),
\end{aligned}
$$

where $D, C$, and $M$ are density, acoustic wave speed, and bulk modulus polynomial coefficients, respectively. Values of $D_{0}$, $D_{1}, D_{2}, C_{0}, C_{1}, C_{2}, M_{0}, M_{1}$, and $M_{2}$ for diesel fuel are 839.4, $0.483,-5.32 \times 10^{-4}, 1359.35,4.05,-5.0 \times 10^{-3}, 1.54 \times 10^{9}, 1.07$ $\times 10^{7}$, and $-2.69 \times 10^{3}$, respectively [9], whereas values of $D_{0}$, $D_{1}, D_{2}, C_{0}, C_{1}, C_{2}, M_{0}, M_{1}$, and $M_{2}$ for RME fuel are 879.379, $0.484,-5.630 \times 10^{-4}, 1405.698,3.691,-4.0 \times 10^{-3}, 1.7328 \times 10^{9}$, $1.0545 \times 10^{7}$, and $-2.838 \times 10^{3}$, respectively [9].

Figure 2 shows the flowchart of nonlinear modeling and gives the computational details of algorithm used for nonlinear model.

\section{Results and Discussions}

Simulated results have been validated by comparing them with previously developed AMESim numerical model of CEUP $[20,21]$. Equation (7) indicates that damping parameter $\alpha$ depends on range of frequencies $\omega$. First portion of (7) is dominant for higher frequencies while second portion is dominant for fractional frequencies. Frequencies range for nonlinear model of CEUP pipeline has been selected considering two important checks; that is, the Nyquist-Shannon sampling theorem is satisfied and the difference between two consecutive nonlinear model predictions is more than

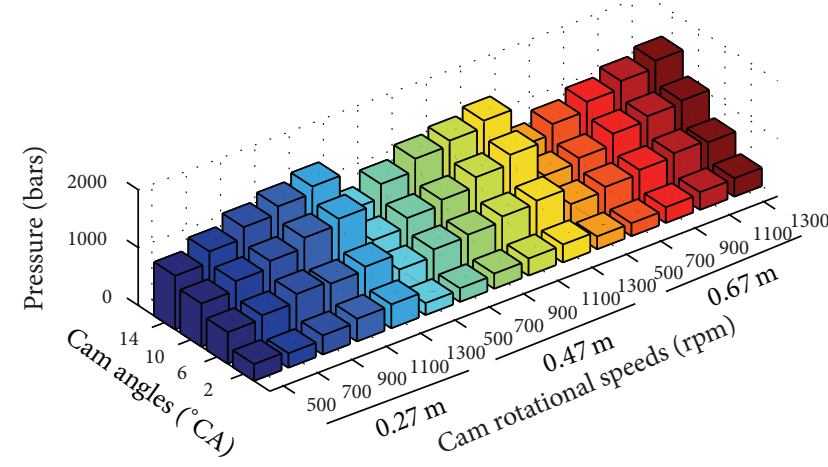

FIgURE 5: Simulated maximum pressures in middle of pipeline.

$5 \%$. First check confirms the lowest frequency while second check confirms the highest frequency that has acceptable effect on predicted pressure wave. It is quite apparent from Figures 3(a)-3(e) that consideration of frequencies lower than $4 \mathrm{MHz}$ would have resulted in inclusion of pressure wave profile which deviates considerably from reference AMESim model. Moreover considering frequencies higher than $40 \mathrm{MHz}$ would have predicted the pressure wave profile with very little or no deviation at all. All predictions of nonlinear frequency dependent mathematical model from $4 \mathrm{MHz}$ to $40 \mathrm{MHz}$ with an increment of $2 \mathrm{MHz}$ have been recorded. Final frequency dependent pressure result is the average of these recorded predictions at various frequencies. Consider

$$
P(f)=\frac{1}{n}\left(\sum_{i=A}^{B} P_{i}\right),
$$

where $n, A$, and $B$ are number of frequencies, lowest frequency, and highest frequency, respectively.

Simulated results with diesel fuel at few frequencies and some of the operating conditions from Table 1 are shown in Figures 3(a)-3(e). Nonlinear frequency dependent model predictions with diesel fuel have been compared with previously developed viscous damped mathematical models $[20,21]$ and AMESim numerical model $[20,21]$ of CEUP fuel injection system in Figures 4(a)-4(e) at various operating conditions of diesel engine. Comparisons validate that developed model predictions are more accurate and coherent as compared to viscous damped mathematical model.

3.1. Effect of Fuel Pipeline Length on Pressure Wave. Nonlinear mathematical model has been simulated at all combinations of operating conditions mentioned in Table 1 with different fuel pipeline lengths. Figure 5 shows comparison of maximum pressure amplitudes in the middle of fuel pipeline with diesel fuel. It can be observed that pressure amplitudes increase with the increase of either cam rotational speeds or cam angles. But there is no significant difference in the pressure amplitudes with the increase of pipeline length at the same cam rotational speeds and cam angles. It confirms that the change in fuel pipeline length does not have much impact on pressure amplitude. 


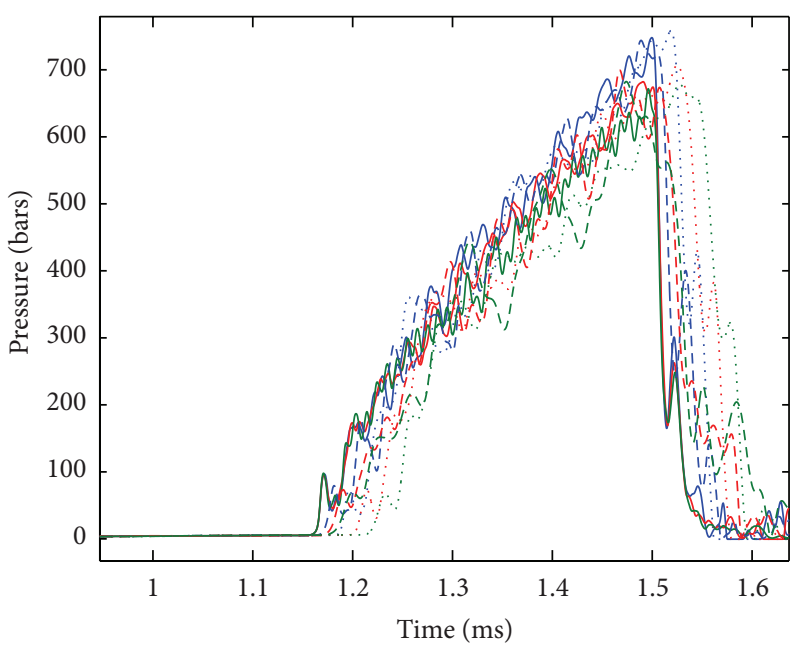

(a)

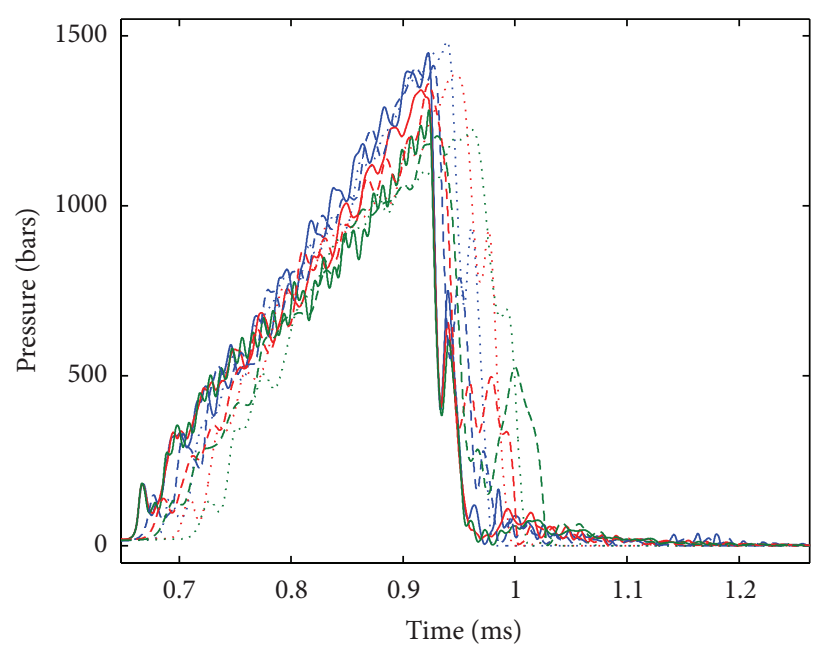

(c)

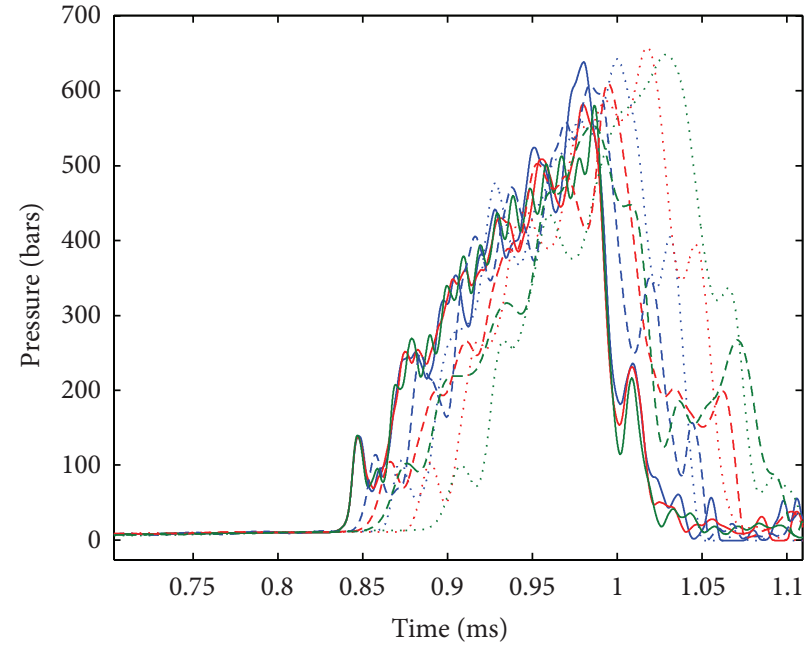

(b)

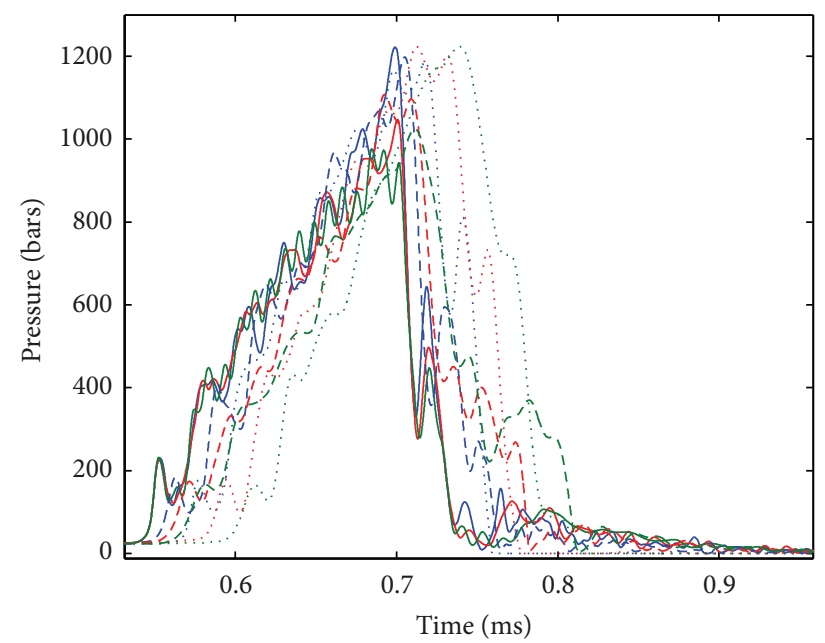

(d)

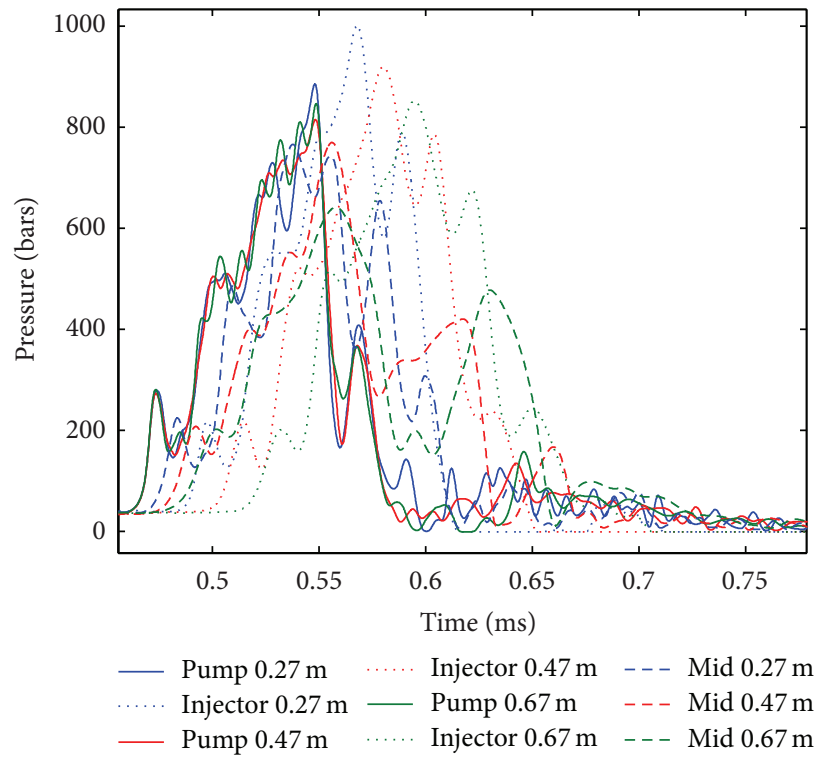

(e)

Figure 6: Pump, injector, and mid pipeline pressures at (a) $500 \mathrm{rpm}, 10^{\circ} \mathrm{CA}$; (b) $700 \mathrm{rpm}, 6^{\circ} \mathrm{CA}$; (c) $900 \mathrm{rpm}, 14^{\circ} \mathrm{CA}$; (d) $1100 \mathrm{rpm}, 10^{\circ} \mathrm{CA}$; and (e) $1300 \mathrm{rpm}, 6^{\circ} \mathrm{CA}$. 


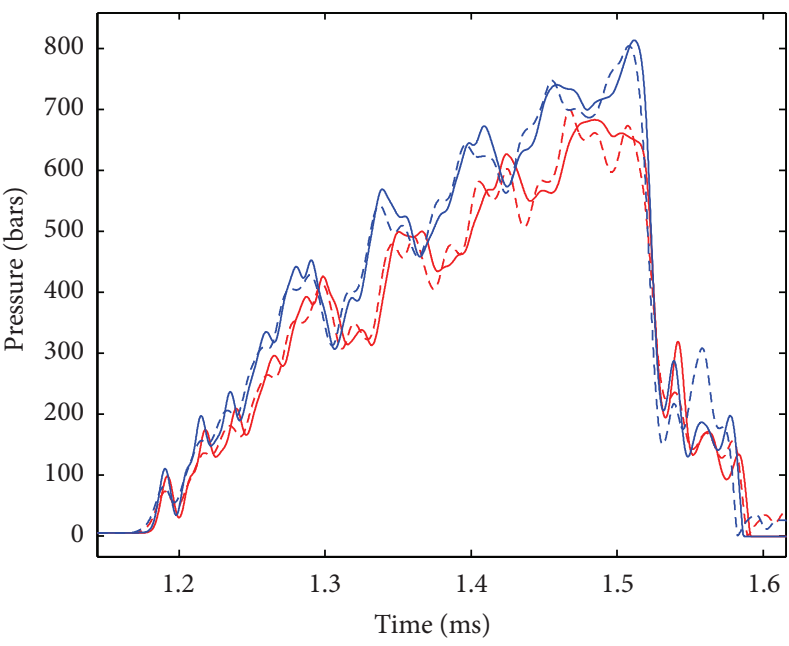

(a)

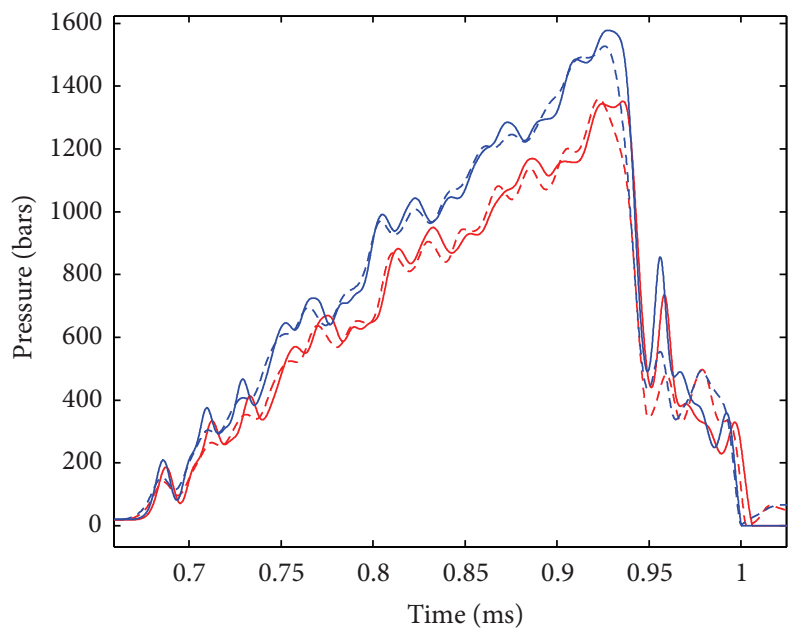

(c)

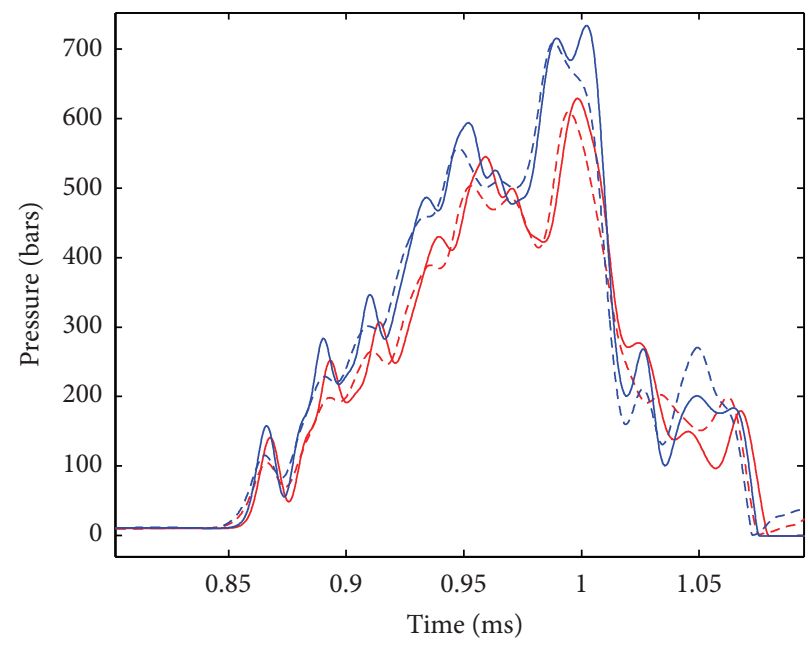

(b)

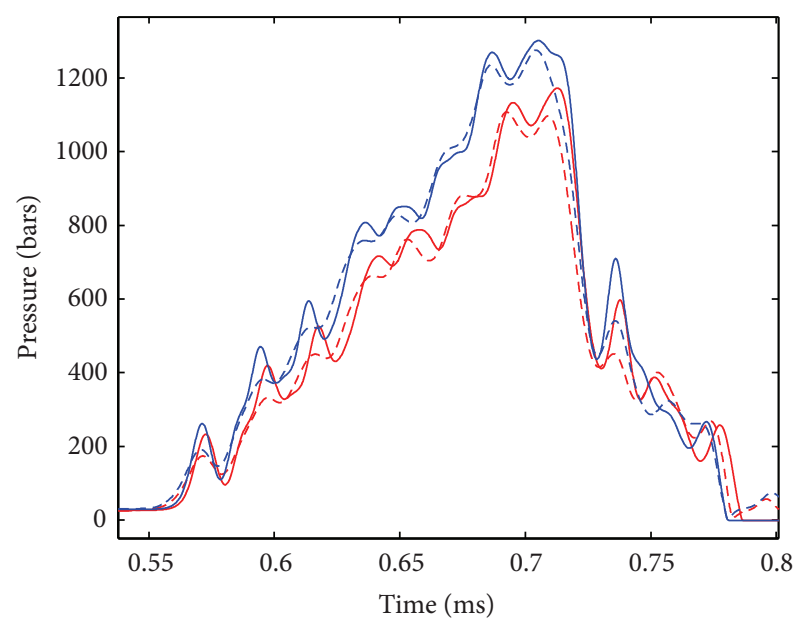

(d)

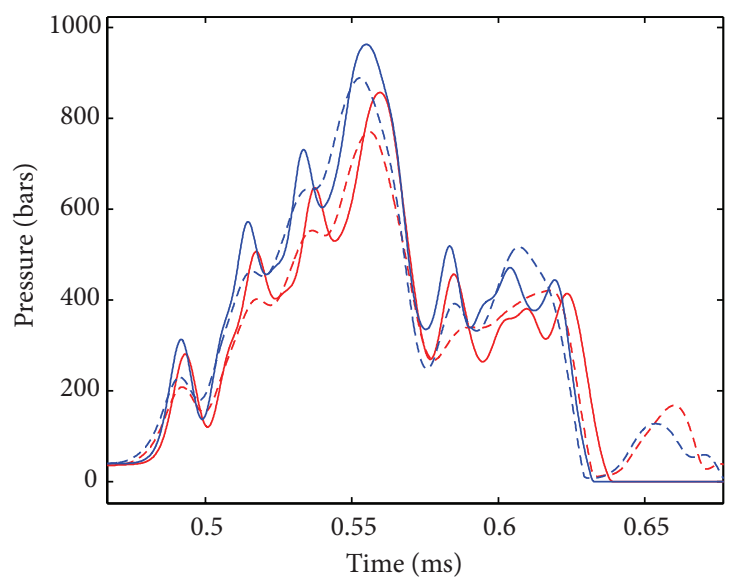

- - MATLAB (diesel) _ - - MATLAB (RME)

- AMESim (diesel) - AMESim (RME)

(e)

Figure 7: AMESim and MATLAB predicted pressures in mid pipeline at (a) $500 \mathrm{rpm}, 10^{\circ} \mathrm{CA}$, (b) $700 \mathrm{rpm}, 6^{\circ} \mathrm{CA}$; (c) $900 \mathrm{rpm}, 14^{\circ} \mathrm{CA}$; (d) $1100 \mathrm{rpm}, 10^{\circ} \mathrm{CA}$; and (e) $1300 \mathrm{rpm}, 6^{\circ} \mathrm{CA}$. 


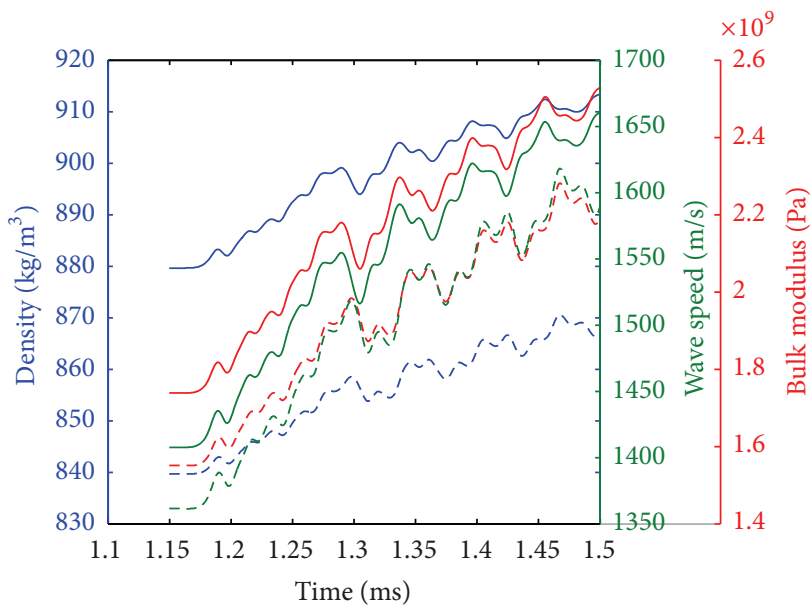

(a)

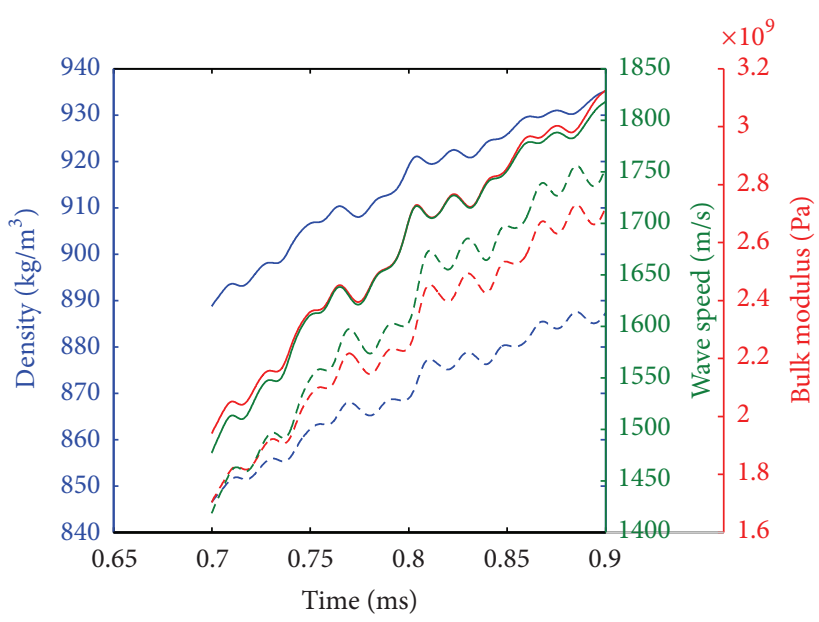

(c)

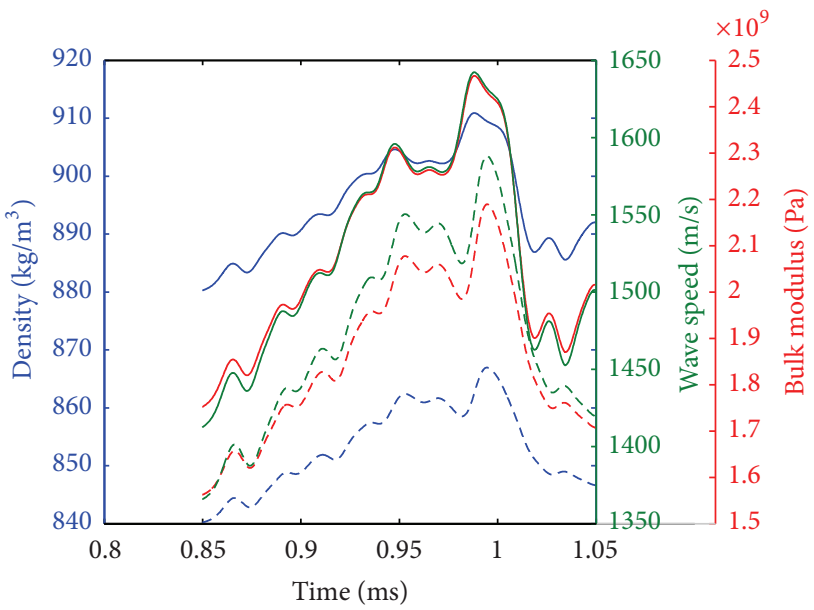

(b)

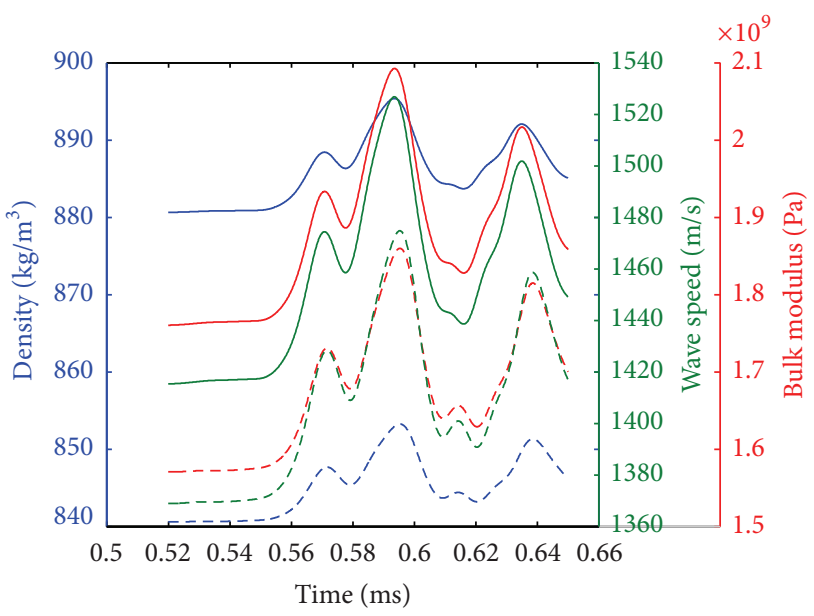

(d)

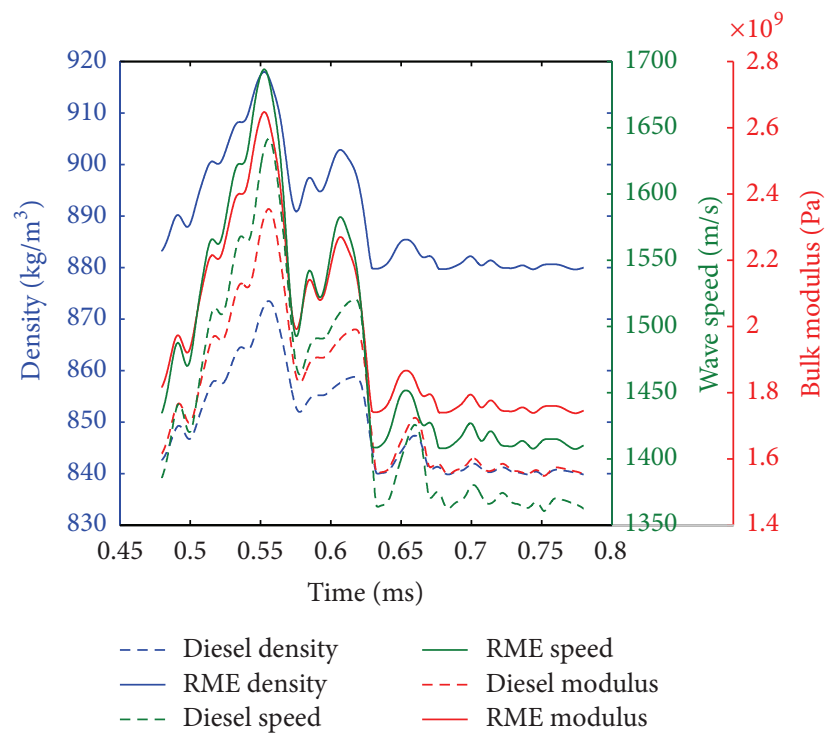

(e)

FIGURE 8: Variations of density, acoustic wave speed bulk modulus at (a) $500 \mathrm{rpm}, 10^{\circ} \mathrm{CA}$; (b) $700 \mathrm{rpm}, 6^{\circ} \mathrm{CA}$; (c) $900 \mathrm{rpm}, 14^{\circ} \mathrm{CA}$; (d) $1100 \mathrm{rpm}$, $2^{\circ} \mathrm{CA}$; and (e) $1300 \mathrm{rpm}, 6^{\circ} \mathrm{CA}$. 
TABLE 2: Maximum densities, acoustic wave speeds, and bulk moduli inside CEUP pipeline with diesel and RME fuel.

\begin{tabular}{|c|c|c|c|c|c|c|c|c|}
\hline \multirow{2}{*}{$\begin{array}{l}\text { S. } \\
\text { number }\end{array}$} & \multirow{2}{*}{$\begin{array}{l}\text { Cam rotational } \\
\text { speeds (rpm) }\end{array}$} & \multirow{2}{*}{$\begin{array}{l}\text { Cam } \\
\text { angles } \\
\left({ }^{\circ} \mathrm{CA}\right)\end{array}$} & \multicolumn{3}{|c|}{ Diesel } & \multicolumn{3}{|c|}{ RME } \\
\hline & & & $\begin{array}{l}\text { Density } \\
\left(\mathrm{kg} / \mathrm{m}^{3}\right)\end{array}$ & $\begin{array}{l}\text { Acoustic wave } \\
\text { speed }(\mathrm{m} / \mathrm{s})\end{array}$ & $\begin{array}{c}\text { Bulk modulus } \\
(\mathrm{GPa})\end{array}$ & $\begin{array}{l}\text { Density } \\
\left(\mathrm{kg} / \mathrm{m}^{3}\right)\end{array}$ & $\begin{array}{c}\text { Acoustic wave } \\
\text { speed }(\mathrm{m} / \mathrm{s})\end{array}$ & $\begin{array}{c}\text { Bulk modulus } \\
(\mathrm{GPa})\end{array}$ \\
\hline \multirow{4}{*}{1} & \multirow{4}{*}{$500 \mathrm{rpm}$} & 2 & 854.754 & 1487.219 & 1.894 & 896.848 & 1537.855 & 2.126 \\
\hline & & 6 & 862.917 & 1554.833 & 2.090 & 906.116 & 1607.357 & 2.349 \\
\hline & & 10 & 870.926 & 1620.744 & 2.289 & 915.171 & 1673.793 & 2.575 \\
\hline & & 14 & 878.888 & 1685.741 & 2.495 & 922.057 & 1723.966 & 2.756 \\
\hline \multirow{4}{*}{2} & \multirow{4}{*}{$700 \mathrm{rpm}$} & 2 & 852.964 & 1472.339 & 1.852 & 896.052 & 1531.879 & 2.108 \\
\hline & & 6 & 868.936 & 1604.409 & 2.238 & 912.491 & 1654.132 & 2.506 \\
\hline & & 10 & 878.270 & 1680.747 & 2.478 & 922.311 & 1725.825 & 2.762 \\
\hline & & 14 & 889.673 & 1772.950 & 2.790 & 933.573 & 1806.422 & 3.077 \\
\hline \multirow{4}{*}{3} & \multirow{4}{*}{$900 \mathrm{rpm}$} & 2 & 855.358 & 1492.239 & 1.909 & 897.314 & 1541.348 & 2.137 \\
\hline & & 6 & 873.624 & 1642.839 & 2.357 & 918.186 & 1695.855 & 2.653 \\
\hline & & 10 & 882.819 & 1717.691 & 2.600 & 928.572 & 1770.802 & 2.935 \\
\hline & & 14 & 896.165 & 1824.790 & 2.978 & 944.104 & 1879.688 & 3.400 \\
\hline \multirow{4}{*}{4} & \multirow{4}{*}{$1100 \mathrm{rpm}$} & 2 & 858.616 & 1519.258 & 1.986 & 901.015 & 1569.045 & 2.225 \\
\hline & & 6 & 878.963 & 1686.392 & 2.497 & 923.371 & 1733.491 & 2.791 \\
\hline & & 10 & 890.580 & 1780.219 & 2.815 & 937.361 & 1833.048 & 3.190 \\
\hline & & 14 & 900.736 & 1860.883 & 3.117 & 944.045 & 1879.211 & 3.399 \\
\hline \multirow{4}{*}{5} & \multirow{4}{*}{$1300 \mathrm{rpm}$} & 2 & 860.648 & 1536.082 & 2.035 & 904.264 & 1593.259 & 2.303 \\
\hline & & 6 & 879.384 & 1689.813 & 2.508 & 925.310 & 1747.476 & 2.844 \\
\hline & & 10 & 899.211 & 1848.928 & 3.069 & 944.930 & 1885.323 & 2.427 \\
\hline & & 14 & 905.087 & 1895.070 & 3.253 & 948.752 & 1911.111 & 3.555 \\
\hline
\end{tabular}

Figures 6(a)-6(e) show comparisons of nonlinear mathematical model simulated pressure results with different pipeline lengths at various cam rotational speeds and cam angles. As depicted from the figure the amplitude of pressure does not change significantly with the increase of pipeline length but the pressure developed at injector side is delayed by some time interval. Moreover considerable change in pressure wave profiles is also observed at the same location with the increase of pipeline length. In Figures 6(a)-6(e) solid lines, dotted lines, and dash lines represent pump side, mid pipe, and injector side pressures, respectively.

3.2. Behavior of Key Fuel Properties. From above discussion it is obvious that profile of the pressure wave changes slightly with the change of fuel pipeline but mostly it is timedelayed at injector side. Therefore behavioral investigation of key fuel properties only for $0.47 \mathrm{~m}$ pipeline has been discussed in this paper. Lab experiments were conducted with both conventional diesel and RME fuels. Pump side and injector side pressure measurements recorded during experiments were observed higher in RME fuel as compared to diesel fuel at the same operating conditions. Similarly simulated nonlinear mathematical model results of pipeline pressure were also observed higher for RME as compared to diesel fuel. Moreover pressure wave profiles with RME fuel were also observed to be varied slightly from diesel fuel but starting time for pressure development remains the same for any particular operating condition. Figures 7(a)-7(e) show comparisons of AMESim and nonlinear model simulated results of both diesel and RME fuels in the middle of pipeline at various cam rotational speeds and cam angles. It is clear from Figures $7(\mathrm{a})-7(\mathrm{e})$ that maximum fuel pressure of RME is always higher than diesel.

Predicted key fuel properties by nonlinear model including densities, acoustic wave speeds, and bulk moduli profiles of both diesel and RME fuel at $500 \mathrm{rpm}, 10^{\circ} \mathrm{CA} ; 700 \mathrm{rpm}$, $6^{\circ} \mathrm{CA} ; 900 \mathrm{rpm}, 14^{\circ} \mathrm{CA} ; 1100 \mathrm{rpm}, 2^{\circ} \mathrm{CA}$; and $1300 \mathrm{rpm}, 6^{\circ} \mathrm{CA}$, respectively, are shown in Figures 8(a)-8(e). Profiles of these key fuel properties of each fuel are nearly similar at the same cam angle but different from other cam angles and type of fuel. It is clear from the figures that density, acoustic wave speed, and bulk modulus increase with the increase of cam angle and that RME fuel has higher values than those of diesel fuel.

Table 2 summarizes maximum values of diesel and RME key fuel properties at various operating conditions predicted by nonlinear model. The peak density, acoustic wave speed, and bulk modulus for both diesel and RME fuels are recorded at $1300 \mathrm{rpm}$ and $14^{\circ} \mathrm{CA}$. Maximum simulated density, acoustic wave speed, and bulk modulus for diesel fuel are $905.087 \mathrm{~kg} / \mathrm{m}^{3}, 1895.070 \mathrm{~m} / \mathrm{s}$, and $3.253 \mathrm{GPa}$ at $1300 \mathrm{rpm}$ and $14^{\circ} \mathrm{CA}$, respectively, whereas maximum simulated density, acoustic wave speed, and bulk modulus for RME fuel are $948.752 \mathrm{~kg} / \mathrm{m}^{3}, 1911.111 \mathrm{~m} / \mathrm{s}$, and $3.555 \mathrm{GPa}$ at $1300 \mathrm{rpm} 14^{\circ} \mathrm{CA}$, respectively. 


\section{Conclusions}

A precise and accurate nonlinear numerical model of pressure inside HP fuel pipeline of CEUP using wave equation including both viscous and frequency dependent frictions has been developed. Frictional effects of various frequencies on pressure wave propagation have been averaged out across valid frequencies to represent the combined effect of all frequencies on pressure wave. Dynamic variations of key fuel properties including density, acoustic wave speed, and bulk modulus with varying pressures have also been incorporated.

Comparisons with previously developed viscous damped numerical and AMESim models confirm that the nonlinear model predictions are more accurate across range of operating conditions of diesel engine.

Nonlinear model has been extended to investigate effect of fuel pipeline and variation of key fuel properties for both diesel and rapeseed methyl ester (RME) for CEUP.

Delay in pressure at injector side has been observed with the increase of fuel pipeline length. Increased fuel pressure and increased key fuel properties amplitude with RME as compared to conventional diesel fuel have been observed. Maximum simulated density, acoustic wave speed, and bulk modulus for diesel fuel are $905.087 \mathrm{~kg} / \mathrm{m}^{3}$, $1895.070 \mathrm{~m} / \mathrm{s}$, and $3.253 \mathrm{GPa}$ at $1300 \mathrm{rpm}$ and $14^{\circ} \mathrm{CA}$, respectively, whereas maximum simulated density, acoustic wave speed, and bulk modulus for RME fuel are $948.752 \mathrm{~kg} / \mathrm{m}^{3}, 1911.111 \mathrm{~m} / \mathrm{s}$, and $3.555 \mathrm{GPa}$ at $1300 \mathrm{rpm} 14^{\circ} \mathrm{CA}$, respectively.

\section{Conflict of Interests}

The authors declare that there is no conflict of interests regarding the publication of this paper.

\section{Acknowledgments}

This work is supported by the National Natural Science Foundation of China (NSFC 51379041, 51279037), Program for New Century Excellent Talents in University (NECT11-0826), the Fundamental Research Funds for the Central Universities (HEUCF13), and the Key Project of Chinese Ministry of Education (113060A).

\section{References}

[1] L. Y. Fan, Q. T. Bing, Y. Chong, H. L. Wen, and Z. M. Xiu, "A study on cycle fuel injection quantity variation for a diesel engine combination electronic unit pump system," Proceedings of the Institution of Mechanical Engineers A: Journal of Power and Energy, vol. 226, no. 5, pp. 712-723, 2012.

[2] L. Y. Fan, X. Z. Yuan, Z. M. Xiu, Q. T. Bing, E. Song, and W. Li, "Quantitative analysis on cycle fuel injection quantity fluctuation of diesel engine electronic in-line pump system," SAE Technical Paper 2010-01-0875, 2010.

[3] L. Y. Fan, W. Long, Y. Zhu, and Y. Xue, "A characteristic study of electronic in-line pump system for diesel engines," SAE Technical Paper 2008-01-0943, 2008.
[4] F. Caresana, "Impact of biodiesel bulk modulus on injection pressure and injection timing. The effect of residual pressure," Fuel, vol. 90, no. 2, pp. 477-485, 2011.

[5] M. Dzida and P. Prusakiewicz, "The effect of temperature and pressure on the physicochemical properties of petroleum diesel oil and biodiesel fuel," Fuel, vol. 87, no. 10-11, pp. 1941-1948, 2008.

[6] B. Kegl and A. Hribernik, "Experimental analysis of injection characteristics using biodiesel fuel," Energy and Fuels, vol. 20, no. 5, pp. 2239-2248, 2006.

[7] A. L. Boehman, D. Morris, J. Szybist, and E. Esen, "The impact of the bulk modulus of diesel fuels on fuel injection timing," Energy and Fuels, vol. 18, no. 6, pp. 1877-1882, 2004.

[8] M. E. Tat and J. H. Van Gerpen, "Effect of temperature and pressure on the speed of sound and isentropic bulk modulus of mixtures of biodiesel and diesel fuel," Journal of the American Oil Chemists' Society, vol. 80, no. 11, pp. 1127-1130, 2003.

[9] B. D. Nikolić, B. Kegl, S. D. Marković, and M. S. Mitrović, "Determining the speed of sound, density and bulk modulus of rapeseed oil, biodiesel and diesel fuel," Thermal Science, vol. 16, supplement 2, pp. S569-S579, 2012.

[10] J. X. Wang, J. X. Lu, J. Y. Zhang, and X. C. Zhang, "Study on several experiential formulas used in simulated calculation of fuel injection process in diesel engines," Vehicle Engine, vol. 5, no. 135, pp. 6-11, 2001.

[11] C. D. Rakopoulos and D. T. Hountalas, "A simulation analysis of a DI diesel engine fuel injection system fitted with a constant pressure valve," Energy Conversion and Management, vol. 37, no. 2, pp. 135-150, 1996.

[12] H.-K. Lee, M. F. Russell, and C. S. Bae, "Mathematical model of diesel fuel injection equipment incorporating non-linear fuel injection," Proceedings of the Institution of Mechanical Engineers D: Journal of Automobile Engineering, vol. 216, no. 3, pp. 191-204, 2002.

[13] A. E. Catania, A. Ferrari, and E. Spessa, "Temperature variations in the simulation of high-pressure injection-system transient flows under cavitation," International Journal of Heat and Mass Transfer, vol. 51, no. 7-8, pp. 2090-2107, 2008.

[14] C. Arcoumanis and R. J. Fairbrother, "Computer simulation of fuel injection systems for DI diesel engines," SAE Technical Paper 922223, 1992.

[15] A. Kristina, Modelling of pressure waves in the common rail diesel injection system [Ph.D. thesis], 2000, http://www.fs.isy.liu.se/ Publications/MSc/00_EX_3081_KA.pdf.

[16] A. Oudina, "Propagation of ultrasonic waves in viscous fluids," in Wave Propagation in Materials for Modern Applications, A. Petrin, Ed., InTech, 2010.

[17] R. Ludwig and P. L. Levin, "Analytical and numerical treatment of pulsed wave propagation into a viscous fluid," IEEE Transactions on Ultrasonics, Ferroelectrics, and Frequency Control, vol. 42, no. 4, pp. 789-792, 1995.

[18] P. M. Jordan, M. R. Meyer, and A. Puri, "Causal implications of viscous damping in compressible fluid flows," Physical Review E-Statistical Physics, Plasmas, Fluids, and Related Interdisciplinary Topics, vol. 62, no. 6 B, pp. 7918-7926, 2000.

[19] J. Herrmann, J. Koreck, M. Maess, L. Gaul, and O. Von Estorff, "Frequency-dependent damping model for the hydroacoustic finite element analysis of fluid-filled pipes with diameter changes," Mechanical Systems and Signal Processing, vol. 25, no. 3, pp. 981-990, 2011. 
[20] H. Qaisar, L. Y. Fan, Z. M. Xiu, and Q. T. Bing, "Comparative study of pressure wave mathematical models for HP fuel pipeline of CEUP at various operating conditions," International Journal on Smart Sensing and Intelligent Systems, vol. 6, no. 3, pp. 1077-1101, 2013.

[21] H. Qaisar, L. Y. Fan, Z. M. Xiu, Q. T. Bing, and F. Naeim, "Analysis of key fuel properties inside combination electronic unit pump fuel pipeline," International Journal on Smart Sensing and Intelligent Systems, vol. 6, no. 5, pp. 2254-2276, 2013. 


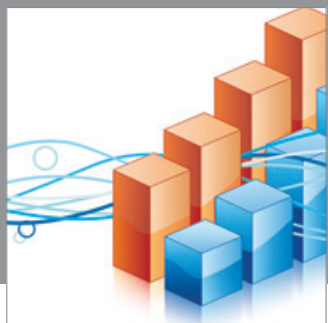

Advances in

Operations Research

mansans

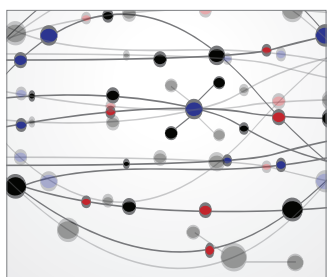

The Scientific World Journal
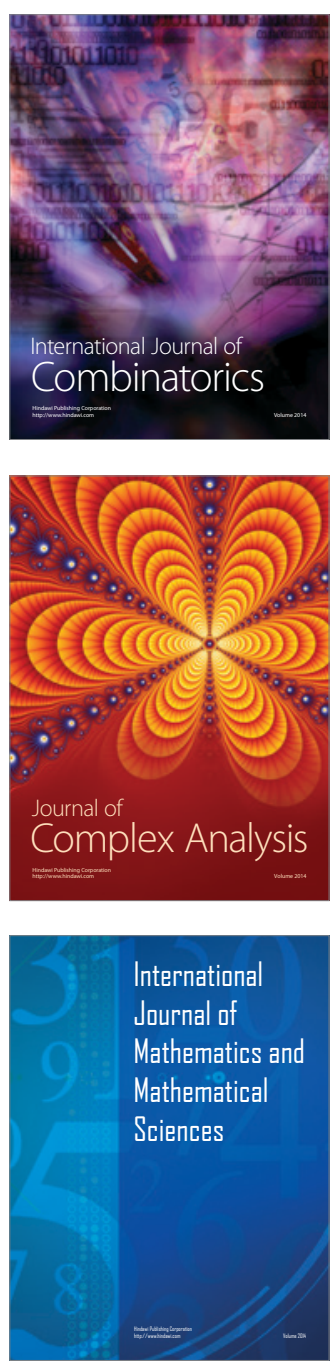
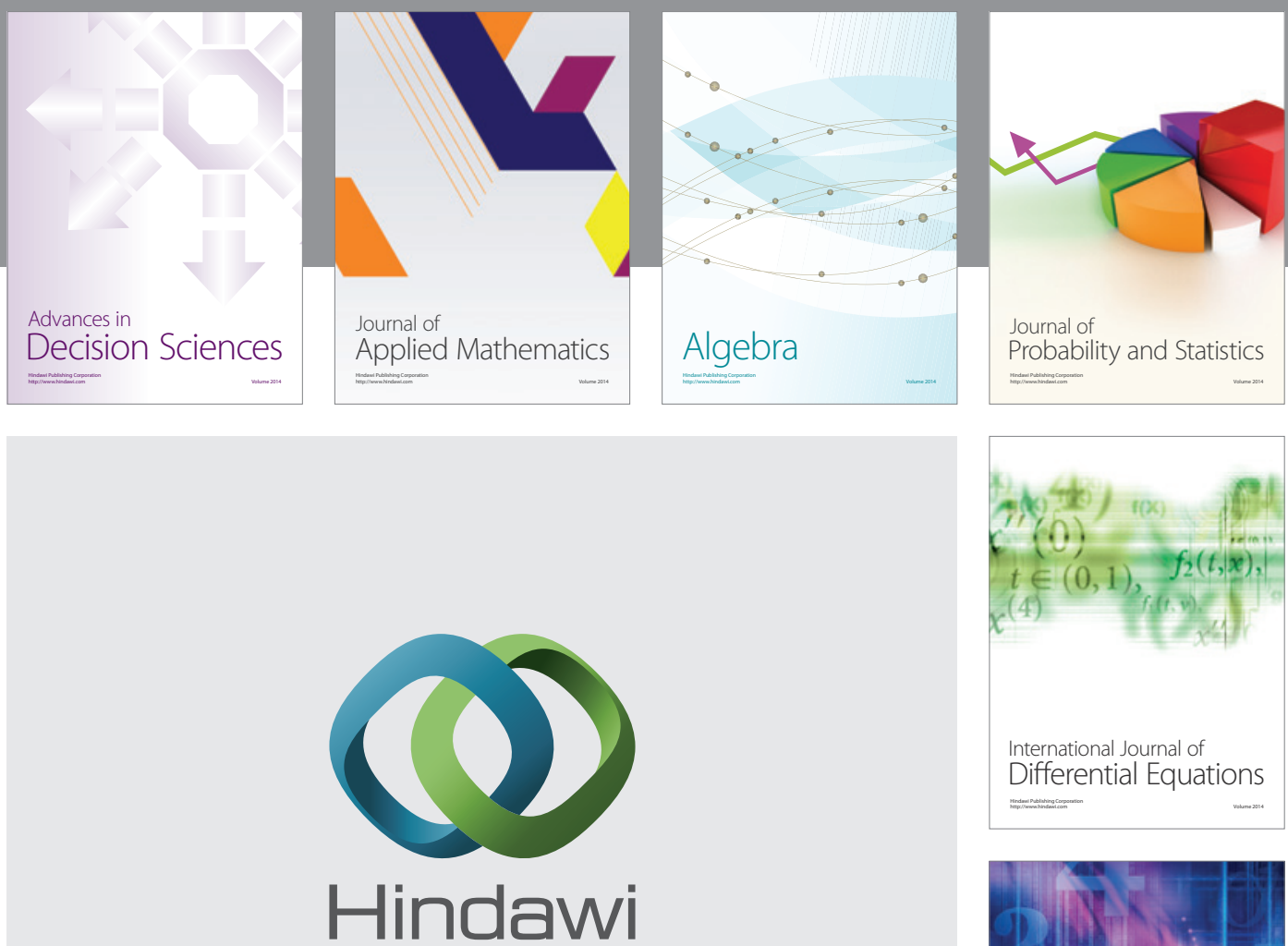

Submit your manuscripts at http://www.hindawi.com
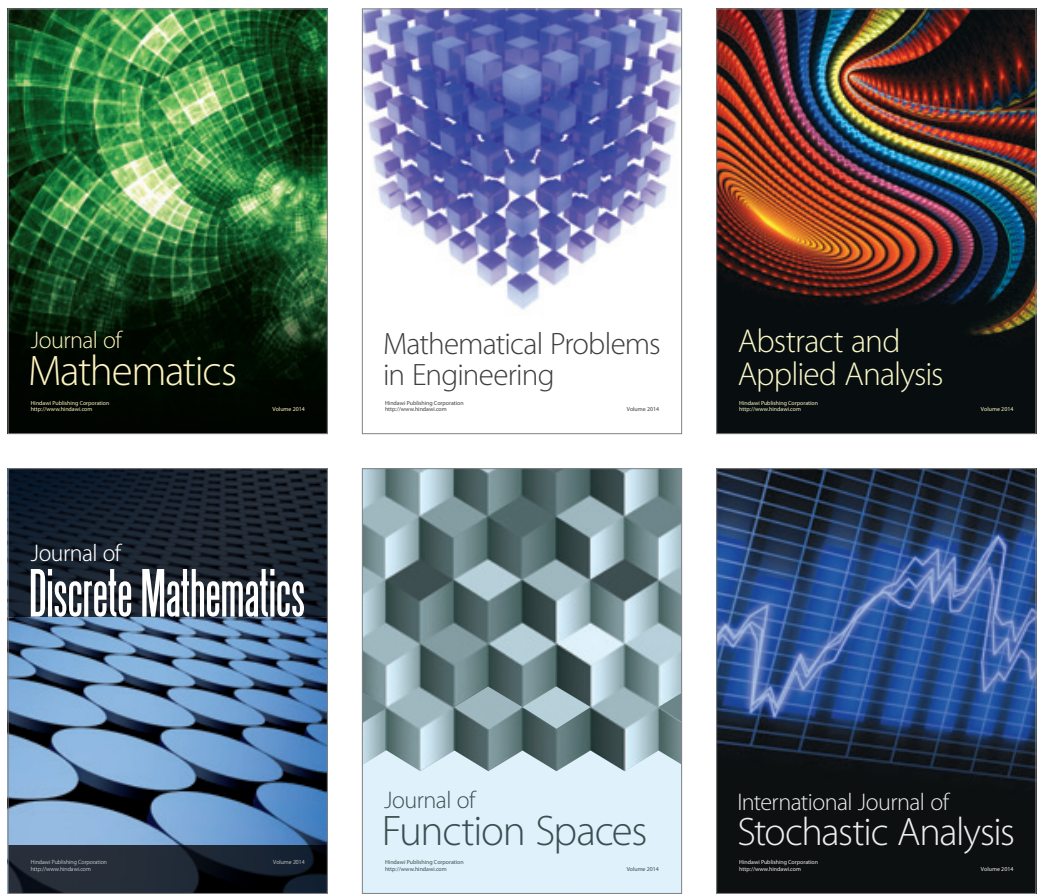

Journal of

Function Spaces

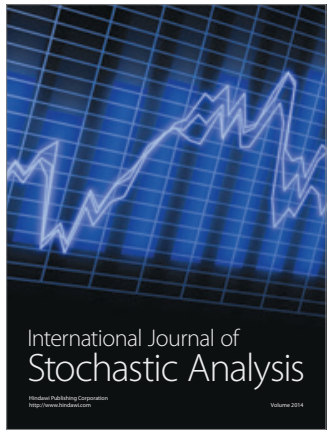

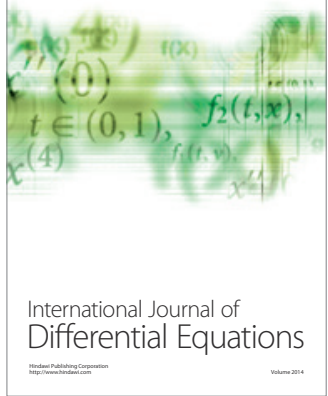
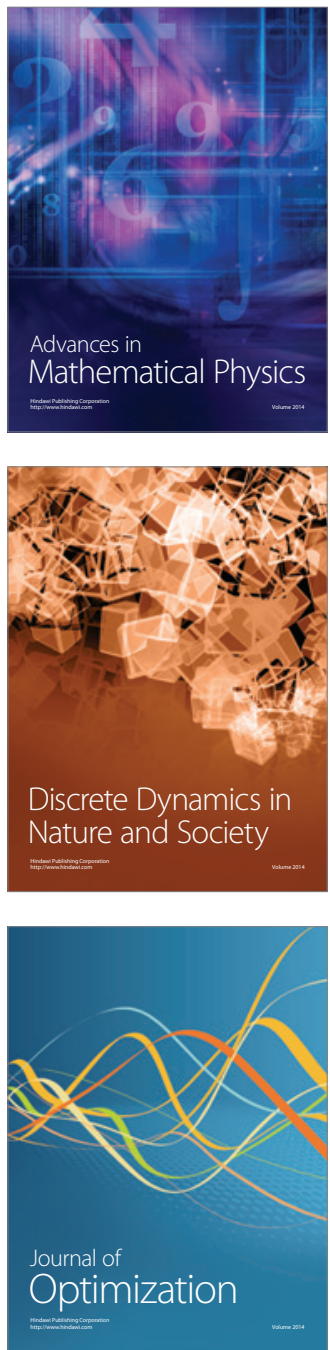